\title{
Perancangan Sistem Informasi Customer Relationship Management (CRM) untuk Meningkatkan Loyalitas dan Pelayanan Customers Berbasis Web dengan Model Waterfall
}

\author{
Hadi Zakaria ${ }^{1}$, dan Aida Eka Marlia ${ }^{2}$ \\ ${ }^{12}$ Program Studi Teknik Informatika, Universitas Pamulang, Tangerang Selatan, Banten, Indonesia \\ e-mail: ${ }^{1}$ dosen00274@unpam.ac.id, ${ }^{2}$ Aidamarlia58@ gmail.com
}

\begin{abstract}
Customer Relationship Management (CRM) is defined as a single unit of sales, marketing and service strategies that prevent uncoordinated work activities between parts well and that depends on coordinated company actions. In this study, the system development model used using the waterfall model is a classic model that is systematic, sequential in building software. The advantage of this model is that the development process is very structured and systematic, through the definition of needs, so that gaps or gaps that occur between the needs and the system produced can be reduced and produce clear development direction for management. Until now, data services are still not integrated, resulting in unsatisfactory service to consumers, the absence of a customer complaint system so that companies can find out complaints in the form of criticism and suggestions to improve service to customers. In this study will build CRM on PT. Srikandi Diamond Motor by using the Waterfall model so that the system is integrated and can improve service to customers and make customer complaints so that companies can find out complaints in the form of criticism and suggestions to improve service to customers. Based on the results of the implementation and testing of this system it can be concluded that the application of data processing systems has been integrated with each other so that it can improve the quality of service to customers, in the implementation of the customer complaint system has been very helpful for companies in knowing complaints in the form of criticism and suggestions to improve service to customers.
\end{abstract}

Kata kunci : Design, Information System, Customers Relationship Management, Waterfall

\section{Pendahuluan}

CRM diartikan sebagai satu kesatuan penjualan, pemasaran dan strategi pelayanan yang mencegah terjadinya aktivitas pekerjaan yang tidak terkoordinasi antarbagian dengan baik dan itu tergantung pada aksi-aksi perusahaan yang terkoordinasi. CRM mendukung suatu perusahaan untuk menyediakan pelayanan kepada pelanggan secara real time dengan menjalin hubungan dengan tiap pelanggan yang berharga melalui penggunaaan informasi tentang pelanggan, berdasarkan apa yang diketahui dari pelanggan, perusahaan dapat membuat variasi penawaran, pelayanan, program, pesan dan media (Kotler, 2003).

\section{Penelitian Terkait}

Pada bagian ini akan diuraikan sedikit tentang penelitian yang sudah dilakukan sebelumnya.

Penelitian yang dilakukan oleh Desi (Desi, 2015) dengan judul "Rancangan Bangun Customer Relationship Management pada jasa servis PT.Global Mobilindo". Metode yang digunakan pada pengembangan sistem ini adalah metode iterasi. PT Global Mobilindo saat ini sering kali mengalami kritikan dari pelanggan tentang kondisi bengkel yang penuh ketika pelanggan akan datang servis dikarenakan menumpuknya kendaraan pelanggan yang belum diambil setelah selesai servis, selain itu pelanggan yang jarang melakukan servis kendaraan di PT Global Mobilindo tidak dapat mengetahui riwayat servis terakhir kali dan terjadinya keluhan pelanggan yang melakukan perbaikan di bengkel lain tiba-tiba mengeluhkan kinerja mekanik PT Global Mobilindo karena dianggap kurang berpengalaman, hal ini menimbulkan kebingungan antara pihak perusahaan dan pihak pelanggan yang tidak mengetahui riwayat servis mereka. Kesalahan dalam pemberian hadiah servis gratis untuk pelanggan tertentu sering kali terjadi, hal ini mengakibatkan menurunnya minat pelanggan untuk melakukan servis pada bengkel PT Global Mobilindo. Aplikasi dibuat untuk mempermudah dalam pendaftaran servis, pengerjaan servis, penjualan suku cadang yang khusus ke servis, penghitungan stok suku cadang servis, pembelian suku cadang khusus kendaraan yang sudah 
selesai dan mempercepat dalam pembuatan laporan servis, laporan pembelian dan penjualan suku cadang, aplikasi adalah perwakilan yang berbasis bahasa dan dapat dibaca mesin dari apa yang seharusnya dilakukan proses perangakat lunak atau bagaimana seharusnya proses perangkat lunak menyelesaikan tugasnya.

Penelitian yang dilakukan oleh Herliyandani (Herliyandani, 2014) dengan judul "Pengelolaan Data Pelanggan Servis Pada Bengkel Motor Ahass 7164 Zahra Motor Semarang". Metode yang digunakan dalam sistem pengembangan ini adalah metode Prototype. Sejauh ini pelayanan yang dilakukan di Bengkel Resmi AHASS 7164 Zahra Motor Semarang masih manual dan belum terkomputerisasi. Pelayanan servis biasanya dilakukan dengan cara memperhitungkan kedatangan pelanggan yaitu dengan melayani pelanggan yang datang awal terlebih dahulu. Tetapi ada kalanya pada musim-musim tertentu bengkel menjadi ramai dan pelanggan menjadi tidak mengetahui kapan proses servis akan dilakukan dan mengakibatkan waktu antrian yang tidak pasti. Situasi menunggu juga merupakan bagian dari keadaan yang terjadi dalam rangkaian kegiatanoperasional yang bersifat acak dalam suatu fasilitas pelayanan. Demikian juga dengan waktu pelayanan servis yang dilakukan di masing-masing bengkel. Dalam membangun aplikasi antrian servis motor, penulis menggunakan desain sistem $U M L$ (Unified Modeling Language) untuk membantu proses perancangan. Penulis mengharapkan dengan adanya aplikasi antrian ini bisa meningkatkan kualitas pelayanan terhadap pelanggan karena dalam aplikasi ini terdapat keterangan estimasi waktu pengerjaan servis motor dan status motor yang masuk dalam daftar antrian dan memiliki manfaat bagi perusahaan untuk bisa mempertahankan dan menambah jumlah pelanggan servis yang datang. Dengan uraian permasalahan di atas penulis menuangkan ide dan gagasan untuk membuat aplikasi antrian yang memberikan kemudahan kepada masyarakat untuk mengetahui sampai di mana status kendaraan yang sedang diservis selain itu diharapkan dapat digunakan untuk pemecahan masalah, sehingga penyedia pelayanan dapat mengusahakan agar dapat melayani pelanggan dengan baik.

\section{Metodologi Penelitian}

Penelitian ini adalah penelitian yang bersifat Kualitatif dan Deskriptif, Penelitian kualitatif adalah pengamatan terhadap obyek penelitian yang menghasilkan suatu konsep atau teori baru terhadap experiment seperti, observasi, wawancara dan studi literatur. Penelitian deskriptif adalah penelitian yang mengumpulkan data untuk pengujian suatu penelitian untuk dasar pengambilan keputusan terhadap experiment seperti pengembangan sistem yang akan dibuat, sehingga langkah-langkah dalam penelitian ini mencakup:

a. Observasi

Observasi dilakukan untuk melengkapi data yang dibutuhkan. Observasi dilakukan dengan mengamati dan melihat dari dekat kegiatan yang dilakukan.

b. Metode Wawancara (Interview)

Dilakukan dengan cara mewawancarai langsung dengan pihak-pihak yang terkait dengan pokok permasalahan yang diteliti agar kelengkapan data lebih baik.

\section{c. Studi Literatur}

Setelah wawancara selesai maka dilakukan pengumpulan informasi dan bahan yang tepat serta memahaminya untuk digunakan dalam pembuatan aplikasi perancangan customer relationship management.

\section{Analisa dan Perancangan}

Metode pengembangan sistem yang penulis gunakan untuk mengembangkan sistem ini yaitu model waterfall yaitu sebuah model perkembangan software yang sistematik dan sekuensial yang mulai pada tingkat dan kemajuan sistem pada seluruh analisis, desain, kode, pengujian, dan pemeliharaan.

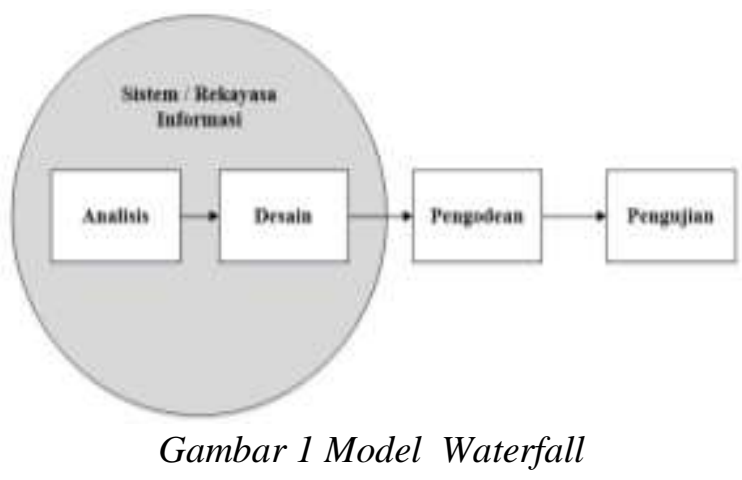

Berikut merupakan tahapan-tahapan pengembangan model Sekuensial Linear (Waterfall Development Model):

\section{Rekayasa dan Pemodelan Sistem Informasi}

Langkah pertama dimulai dengan membangun keseluruhan elemen sistem dan 
memilah bagian-bagian mana yang akan dijadikan bahan pengembangan perangkat lunak, dengan memperhatikan hubungannya dengan Hardware, User, dan Database.

\section{Analisis kebutuhan perangkat lunak}

Pada proses ini, dilakukan penganalisaan dan pengumpulan kebutuhan sistem yang meliputi domain informasi, fungsi yang dibutuhkan unjuk kerja/performansi dan antarmuka. Hasil penganalisaan dan pengumpulan tersebut didokumentasikan dan diperlihatkan kembali kepada pelanggan.

\section{Desain}

Pada proses desain, dilakukan penerjemahan syarat kebutuhan sebuah perancangan perangkat lunak yang dapat diperkirakan sebelum dibuatnya proses pengkodean (coding). Proses ini berfokus pada struktur data, arsitektur perangkat lunak, representasi interface, dan detail algoritma prosedural.

\section{Pengkodean}

Pengkodean merupakan proses menterjemahkan perancangan desain ke bentuk yang dapat dimengerti oleh mesin, dengan menggunakan bahasa pemrograman.

\section{Pengujian}

Setelah proses pengkodean selesai, dilanjutkan dengan proses pengujian pada program perangkat lunak, baik Pengujian logika internal, maupun pengujian eksternal fungsional untuk memeriksa segala kemungkinan terjadinya kesalahan dan memeriksa apakah hasil dari pengembangan tersebut sesuai dengan hasil yang diinginkan

\section{Analisa Sistem Informasi Customers \\ Relationship Management (CRM)}

Analisa sistem informasi kepegawaian saat ini di PT. Srikandi Diamond Motors dibuat oleh peneliti dalam bentuk use case diagram dan activity diagram, karena kedua notasi UML ini mewakili secara sederhana dan bisa dijadikan sebagai bahan dalam evaluasi sistem yang berjalan secara efektif, sehingga sistem dapat terlihat tanpa harus mengetahui secara detail prosedur yang berjalan.

Kegiatan yang dilakukan sistem yang berjalan saat ini digambarkan menggunakan use case diagram dan activity diagram, yang digambarkan di dalam gambar yang ada di bawah ini:

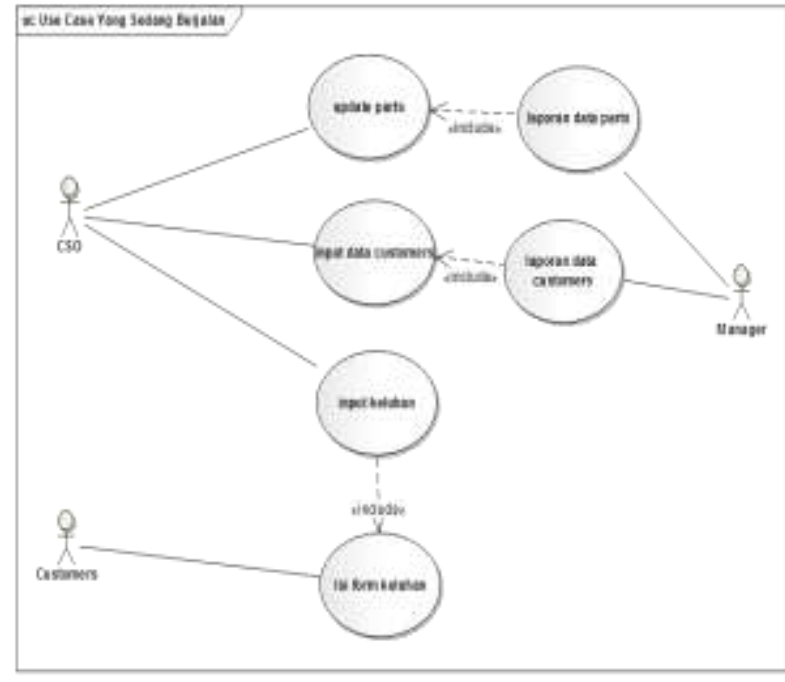

Gambar 2 Use Case Diagram Analisa Sistem CRM

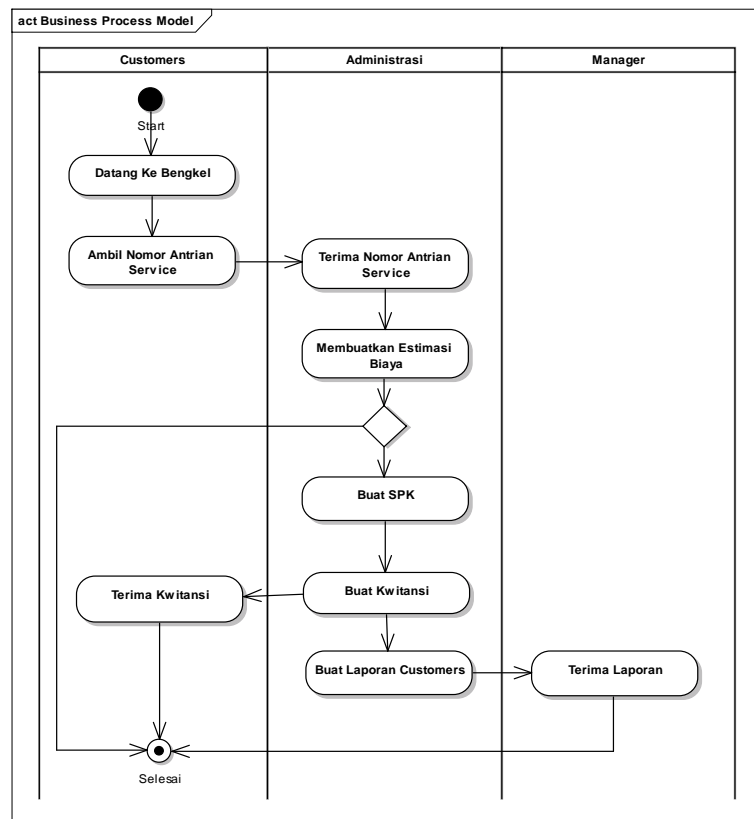

Gambar 3 Activity Diagram Sistem yang Berjalan

\section{Activity Diagram Sistem yang masih berjalan di PT. Srikandi Diamond Motors.}

Pada Gambar 3 menjelaskan aktivitas yang dilakukan adalah customers datang ke bengkel untuk melakukan service kendaraan, kemudian mengambil nomor antrian untuk menunggu panggilan oleh bagian administrasi, setelah dipanggil maka administrasi akan membuatkan estimasi biaya service yang akan diberikan kepada customers, jika customers tidak setuju maka service tidak dapat dilanjutkan, namun jika setuju maka administrasi akan membuatkan surat 
perintah kerja kepada mekanik, yang selanjutnya jika mekanik sudah selesai dalam memperbaiki kendaraan tersebut, administrasi akan membuatkan kwitansi biaya service kepada customers, dan membuatkan laporan kepada manager.

\section{Evaluasi Sistem Saat Ini}

Tabel 1 Permasalahan dan Solusinya

\begin{tabular}{|c|c|c|}
\hline Masalah & Aktor & Aktor \\
\hline $\begin{array}{l}\text { Pelayanan data } \\
\text { masih } \\
\text { terintegrasi } \\
\text { sehingga } \\
\text { mengakibatkan } \\
\text { pelayanan pada } \\
\text { konsumen kurang } \\
\text { memuaskan. } \\
\end{array}$ & $\begin{array}{l}\text { Administrasi, } \\
\text { Staff } \\
\text { Gudang, } \\
\text { Kasir }\end{array}$ & $\begin{array}{l}\text { Agar sistem } \\
\text { saling } \\
\text { terintegrasi dan } \\
\text { meningkatkan } \\
\text { pelayanan pada } \\
\text { Customer }\end{array}$ \\
\hline $\begin{array}{l}\text { Belum adanya } \\
\text { sistem } \text { customer } \\
\text { complaint agar } \\
\text { perusahaan dapat } \\
\text { mengetahui keluhan } \\
\text { berupa kritik dan } \\
\text { saran untuk } \\
\text { meningkatkan } \\
\text { pelayanan terhadap } \\
\text { customers. }\end{array}$ & $\begin{array}{l}\text { Customers, } \\
\text { Manager, } \\
\text { Mekanik }\end{array}$ & $\begin{array}{l}\text { Agar } \\
\text { perusahaan } \\
\text { dapat } \\
\text { mengetahui } \\
\text { keluhan berupa } \\
\text { kritik dan saran } \\
\text { untuk } \\
\text { meningkatkan } \\
\text { pelayanan } \\
\text { terhadap } \\
\text { customer. }\end{array}$ \\
\hline
\end{tabular}

Berdasarkan dari sistem informasi customers relationship management yang sudah berjalan, bahwa kegiatan proses mulai dari pendaftaran service sampai selesai masih banyak kekurangan, adapun kekurangannnya adalah sebagai berikut:

a. Sistem pengelolaan yang digunakan untuk pengelolaan data perusahaan belum terintegrasi seperti sistem estimasi biaya, stock parts, data customers, dan data suppliers sehingga pengelolaan data masih kurang efisien.

b. Sistem booking masih menggunakan cara konvensional seperti booking masih melalui telepon dan datang langsung, sehingga antrian di customers service menjadi banyak.

\section{Perancangan Basis Data}

Dalam hal ini akan digunakan Entity Relationship Diagram (ERD) untuk merancang basis data. ERD yang merupakan hasil analisis sebagai berikut:

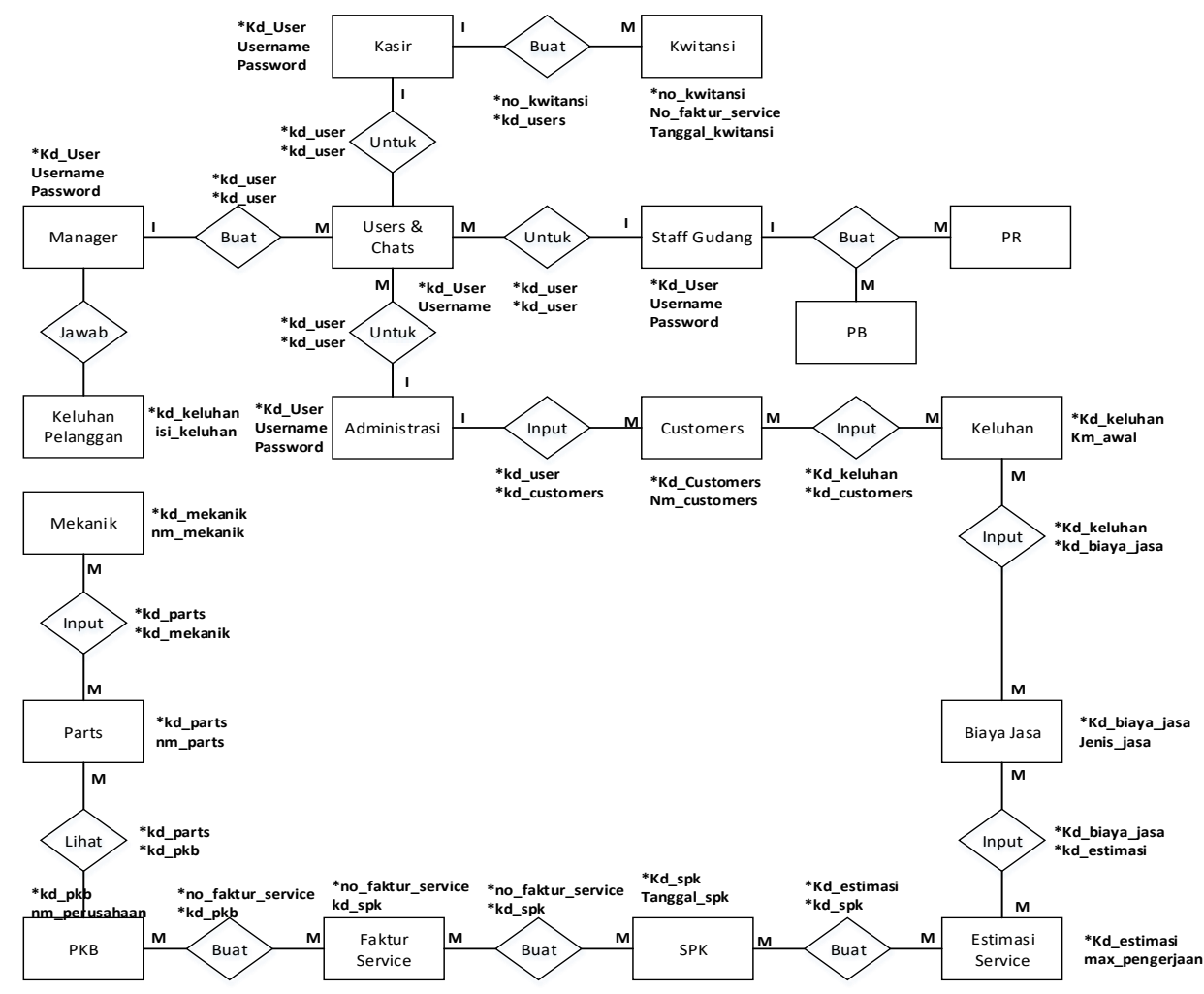

Gambar 4 Entity Relationship Diagram 
Diagram ERD di atas menggambarkan struktur database yang akan dibangun dalam sistem Customers Relationship Management $(C R M)$.

\section{Implementasi}

a. Administrasi

1. Form Login

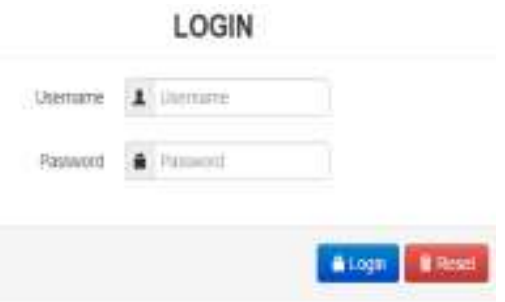

Gambar 5 Form Login Admin

Form ini berfungsi sebagai halaman login untuk administrasi. Untuk mengakses halaman admin, agar dapat melakukan semua transaksi.

\section{Form Data Customers}

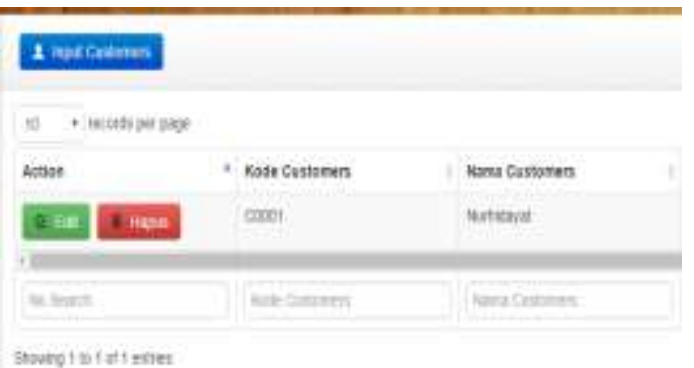

Gambar 6 Form Data Customers

Berfungsi sebagai halaman untuk melakukan transaksi data customers seperti input, edit, dan hapus data customers.

3. Form Keluhan Customers

\section{t wowkenta:}

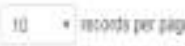

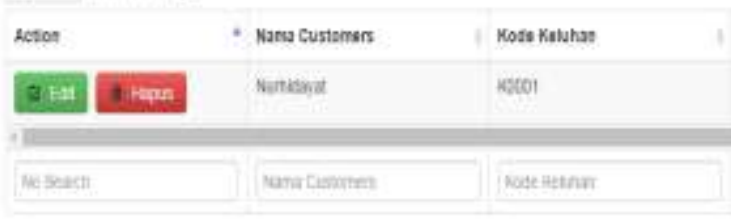

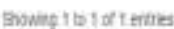

\section{Gambar 7 Form Keluhan Customers}

Berfungsi sebagai halaman untuk melakukan transaksi data keluhan seperti input, edit, dan hapus data keluhan.

4. Form Perjanjian Kerja Bersama

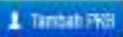

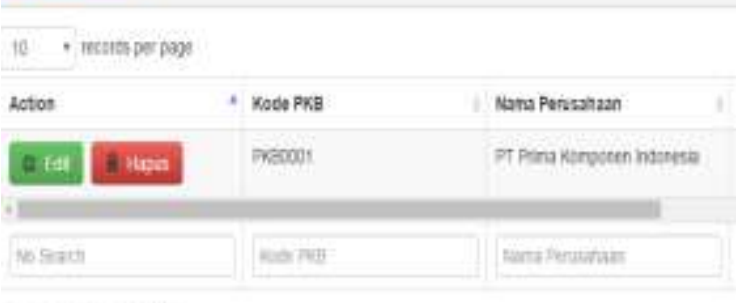

Bhowerp ito 1 of 1 ames

Gambar 8 Form Perjanjian Kerja Bersama

Berfungsi sebagai halaman untuk melakukan transaksi data perjanjian kerja bersama seperti input, edit, dan hapus data perjanjian kerja bersama.

5. Form Data Mekanik

\section{Thatuen}

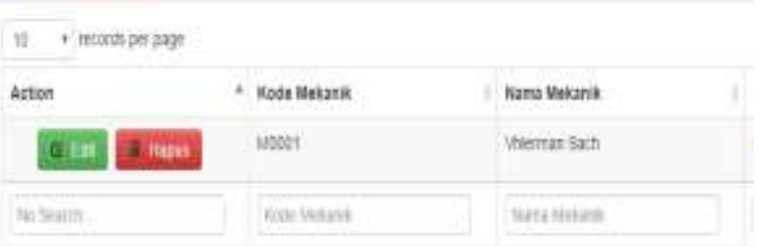

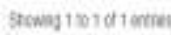

Gambar 9 Form Data Mekanik

Berfungsi sebagai halaman untuk melakukan transaksi data mekanik seperti input, edit, dan hapus data mekanik. 
6. Form Biaya Jasa

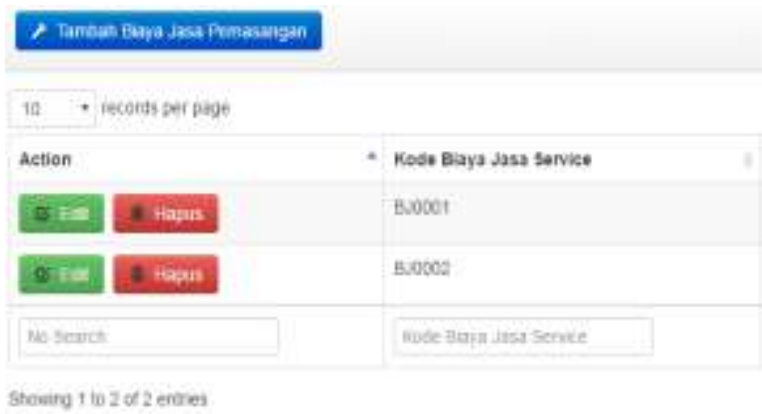

Gambar 10 Form Data Biaya Jasa

Berfungsi sebagai halaman untuk melakukan transaksi data biaya jasa seperti input, edit, dan hapus data biaya jasa.

7. Form Data Parts

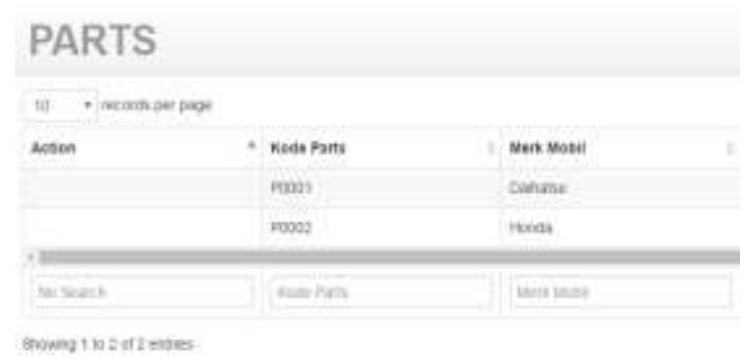

Gambar 11 Form Data Parts

Berfungsi sebagai halaman untuk melihat stock parts yang tersedia.

8. Form Estimasi Service

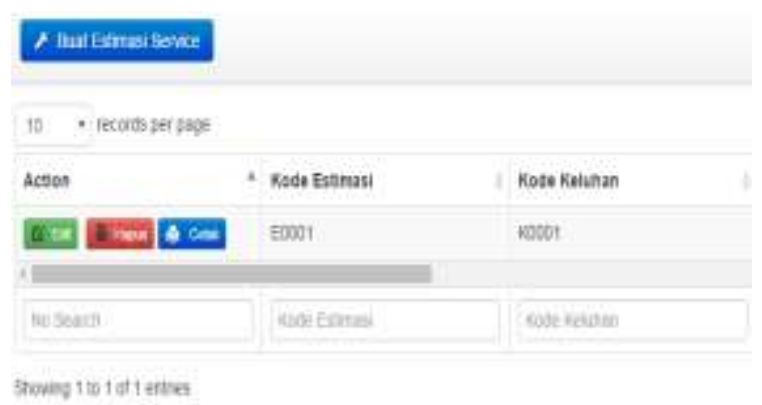

Gambar 12 Form Data Estimasi Service

Berfungsi sebagai halaman untuk melakukan transaksi data estimasi service seperti input, edit, cetak dan hapus data estimasi service.
9. Form Status PR

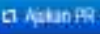

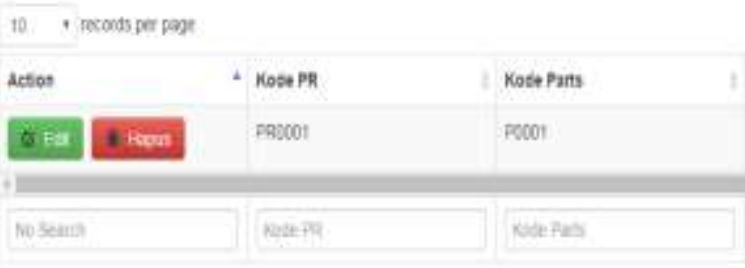

Showeg 1 of 1 st 1 erties

Gambar 13 Form Data PR

Berfungsi sebagai halaman untuk melakukan transaksi data pr seperti ajukan pr edit, dan hapus data pr.

10. Form Buat SPK

\section{$>\operatorname{sinsk}$}

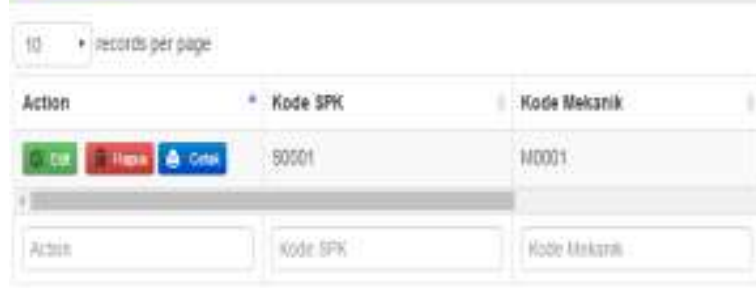

Shenry 101 d t 1 anter

Gambar 14 Form Data SPK

Berfungsi sebagai halaman untuk melakukan transaksi data SPK seperti buat SPK edit, cetak, dan hapus data SPK.

11. Form Buat Faktur Service

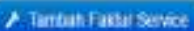

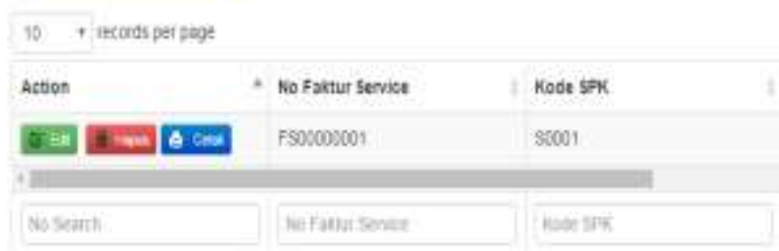

Shouleg 1 ss 1 of t euses

Gambar 15 Form Data Faktur Service

Berfungsi sebagai halaman untuk melakukan transaksi data Faktur Service 
seperti tambah faktur, edit, cetak, dan hapus data faktur service.

\section{Kesimpulan}

Berdasarkan hasil implementasi dan pengujian sistem CRM ini disimpulkan bahwa:

a. Dalam penerapan sistem pengolahan data sudah berintegrasi satu sama lain sehingga dapat meningkatkan kualitas pelayanan terhadap customer

b. Dalam penerapan sistem customer complaint sudah sangat membantu perusahaan dalam mengetahui keluhan berupa kritik dan saran untuk meningkatkan pelayanan terhadap customers.

\section{Saran}

Dari hasil implementasi dan pengujian ini, penulis menyadari masih terdapat banyak kekurangan dalam pengembangan sistem ini. Saran-saran yang dapat peneliti berikan antara lain:

a. Sistem informasi ini masih dapat dikembangkan dengan aplikasi yang serupa, peneliti mengharapkan untuk lebih baik lagi fungsi-fungsi dari aplikasi tersebut seperti fungsi pembayaran debit yang langsung divalidasi oleh pihak bank.

b. Sistem informasi ini masih dapat dikembangkan dan diintegrasikan dengan aplikasi android, sehingga dalam proses booking service langsung mengakses aplikasi tersebut. Sistem informasi ini masih dapat dikembangkan dengan berbagai framework PHP, seperti laravel, yii, dan codeigniter, sehingga dalam penulisan script kode menjadi lebih ringkas dan terstruktur dengan baik.

\section{Referensi}

Kadir, A. (2013) Pengenalan Sistem Informasi. Yogyakarta: Andi Offset.

Wardhana, A. (2013) Pengaruh Kualitas Pelayanan dan Citra Merek Bengkel Resmi Terhadap Nilai Pelanggan Serta Implikasinya Pada Kepuasan Pelanggan (Suatu Survey Pada Pelanggan Bengkel Resmi Kendaraan Mpv di Bawah 2500 cc di kota bandung). Vol.2 No.3, Januari 2013.

Sukoco, A. A. (2003) I-CRM Membina Relasi Dengan Pelanggan. Yogyakarta: Andi

Anamisa, D. R. (2010) Pemrograman Basis Data Berbasis Web Menggunakan PHP Dan $M y S Q L$. Yogyakarta: Graha Ilmu.
Ersi D. Y. \& Semuel, H. (2014) Analysis CRM, Kepuasan Pelanggan dan Loyalitas Produk Ukm Berbasis Bahan Baku Terigu di Jawa Timur. Vol. 8, No. 1, April 2014

Sitindaon, F. (2003) Membuat Aplikasi Web Database Dinamis Menggunakan Paket Open Source. Jakarta: Elex Media Komputindo.

Alatas, A. (2013) Responsive Web Design Dengan PHP Dan Bootstrap. Yogyakarta: Lokomedia.

Al-Amin, I. H, \& Kristanto A. (2014) Aplikasi Customer Relationship Management (CRM) di cv. Matahari Digital Printing Semarang. Vol 8 No 2 Juli 2014, h.49 - 65.

Imasari, K, \& Nursalin, K. K. (2011) Pengaruh Customer Relationship Management Terhadap Loyalitas Pelanggan Pada PT BCA Tbk Influence of Customer Relationship Management Toward Customer Loyalty on PT. BCA Tbk. Vol. 10, No. 3, Desember 2011.

Ladjamudin, A. B. 2005. Analis dan Desain Sistem Informasi. Yogyakarta : Graha Ilmu.

Afrina, M. \& Ibrahim, A. (2013). Rancang Bangun Electronic Costumer Relationship Management (E-CRM) Sebagai Sistem Informasi Dalam Peningkatan Layanan Perpustakaan Digital Fakultas Ilmu Komputer Unsri. VOL. 5, NO. 2, Oktober 2013.

Oetomo \& Dharma, B. S. (2007) Pengantar Teknologi Informasi Internet: Konsep dan Aplikasi. Yogyakarta: Andi.

Kotler, P. (2003) Marketing Management. Jilid 2 Edisi 13. Erlangga.2003

Rohy (2014) Smart Trik JQuery Without Plugin. Yogyakarta: Andi Offset.

Rosa, A. S. \& Shalahuddin, M. 2013. Rekayasa Perangkat Lunak Terstruktur Dan Berorientasi Objek. Bandung: Informatika Bandung.

Kusnandar, T. 2011. Penerapan CRM Dengan Sistem Informasi Berbasis Web Untuk Kepuasan Pelanggan. Vol. 5, No. 1, Juni 2011, 6-13. 